\title{
Fieldwork during a pandemic: Navigating personal grief and practicing researcher flexibility
}

\section{Karina Santellano ${ }^{1}$}

Accepted: 15 July 2021 / Published online: 31 January 2022

(C) The Author(s), under exclusive licence to Springer Nature Limited 2022

White supremacy, racial capitalism, heteropatriarchy, and other systems of oppression exploit and disadvantage Latinx populations in the labor market, in educational settings, in health care and in other realms of US society. These structural inequalities have been exacerbated during the pandemic for low-income and working-class Latinxs, particularly those who live in dense housing with limited space to properly physically distance and those who work in essential businesses like grocery stores and restaurants (Lin and Money 2021). The mismanagement of the pandemic by the federal administration facilitated the anguish and death that vulnerable Latinx, African Americans, and Indigenous people experienced across the country. As of June 2021, more than 108,000 Latinxs in the United States have died because of COVID19 (Centers for Disease Control and Prevention 2021).

In both San Diego, California, where I was born and raised, and Los Angeles, where I am currently pursuing my doctorate in sociology, COVID-19 cases skyrocketed in December 2020 and January 2021 (Lin and Money 2021). Patients with COVID-19 overwhelmed hospitals so much that hospitals in these two counties reached 100\% capacity (Mester and Lyster 2020). Ambulances carrying sick patients were forced to keep patients for hours until hospital beds became available (Meeks et al. 2021). Unfortunately, the COVID-19 devastation around me was magnified for two main reasons. The first was that my own grandfather, who lived in our multigenerational household for most of my life and who I loved deeply, died in late November 2020 because of COVID-19 and underlying health conditions within hours of being admitted to the hospital. Two weeks later, his son, my father, was hospitalized with COVID-19 on the same afternoon that he buried his father. This meant that my three brothers and I became responsible for our parents' home mortgage, utility bills, grocery needs, and other expenses on top of our own living expenses overnight. It was overwhelming to grieve my grandfather's loss, process my dad's deteriorating health, and determine what I could eliminate from my already strained graduate student budget to assist my family.

Karina Santellano

ksantell@usc.edu

1 University of Southern California, Los Angeles, USA 
The second reason the COVID-19 has been devastating is that Southern California is my home, and its Latinx people, places, and things inspire my sociological research. As I am a Mexican American woman from a poor working-class background, my work aims to advance our understandings of the relationship between capitalism and ethnorace by examining how Latinxs themselves are using Latinx identity in creative business ventures - specifically, Latinx-inspired coffee shopsthat reshape and, in some moments, reify ethnorace itself; hold nostalgic meaning for Latinx customers; and transform surrounding neighborhoods. Certainly, if I was experiencing COVID-19-related familial death and illness, I knew that my Latinx research participants, many of whom are the children of Latin American immigrants, most likely were as well. Therefore, the magnitude of the grief and trauma in Southern California was intensely palpable for me.

In this Vivencia, I recall experiences from my dissertation interviews during COVID-19 with Ernesto (pseudonym) and other research participants, for two reasons. The first is to acknowledge the experiences that Latinx researchers, particularly those from working-class backgrounds, may have experienced and/or continue to experience during the pandemic. I realize that there may be many of us who are navigating the grief and trauma of losing a loved one or taking care of a loved one(s). The second is to encourage scholars to practice understanding and flexibility toward research participants, and toward ourselves, in the data collection process, and especially in unprecedented times like the pandemic.

Therefore, I start with my connection to Ernesto. Ernesto and his two business partners own a Latinx-themed coffee shop in a neighborhood in the South Los Angeles area. Ernesto's coffee shop sells freshly made churros with dips like melted Abuelita chocolate and Mexican cajeta. The coffee shop also sells drinks like the horchata latte, the mazapán frappe, and the Bubulubu (a popular Mexican chocolate bar brand) cappuccino. I had approached Ernesto for an interview to primarily discuss his coffee shop, but we bonded over our common experience of being upwardly mobile Latinx millennials with immigrant fathers who had caught COVID-19 and were now fighting to stay alive.

\section{Bonded by COVID-19 grief}

On a dreary January 2021 morning in South Los Angeles, I interviewed Ernesto. We sat in multicolored chairs in the outside patio of his coffee shop. As I set up my iPad to record our conversation, Ernesto asked me how my Dad was doing. We did not know much about each other, but we had communicated on the social media app Instagram to set up an interview back in early December. However, just a few hours before heading over to his coffee shop on that December day, I had to cancel my interview with Ernesto because my Dad had just been intubated and connected to a ventilator in a San Diego hospital. Prior to his intubation, my Dad had been in the hospital for two weeks and was receiving oxygen through a breathing mask. My family and I hoped and prayed that the breathing mask would be the extent of his hospital treatment, but clearly it was not. 
Upon learning of my Dad's intubation on that December 2020 day, I knew that I was not in the best mental space to conduct a research interview. I was concerned for my Dad, because I knew that being intubated and on a ventilator was not a good sign. Rather, it signaled that his health was worsening. I was heartbroken. I felt that he had too many years left to live and too many memories to make with our family. I informed Ernesto of my cancellation and of my Dad's intubation. I then spent the rest of the afternoon under my bed covers processing my grief.

Weeks later, in late December, when my Dad's health seemed to stabilize (although still on a ventilator), I reached out to Ernesto to reschedule our interview, as I was curious to learn about his journey as an entrepreneur and his coffee shop. I needed the mental and emotional relief, even for a few hours or even minutes during the week, from the grief I was experiencing from my grandfather's passing and my dad's long-term hospitalization. Although no one pressured me to get any dissertation work done during this time, I did choose to work on my dissertation when I could. My health-care team, composed of my therapist and psychiatrist, as well as my Latina $\mathrm{PhD}$ graduate colleagues at USC, and others sent so much love my way that I felt the strength to continue pursuing my work.

Ernesto replied to my message a few days later, and he notified me that he and his entire family, including his parents and pregnant girlfriend, had tested positive for the coronavirus. Although they knew it was not the wisest decision to celebrate Christmas together, they had, and someone had infected the rest of the family. The news felt very heavy to me. Ernesto offered to do the interview with me on Zoom. However, since he was ill, we jointly decided it would be better to check in with each other in a few weeks.

In January 2021, I reached out to Ernesto once more to ask him how he and his family were doing. He shared that he and his family members had fully recovered with the exception of his Dad. His Dad had been hospitalized, intubated and on a ventilator, in critical condition in a Los Angeles hospital. Ernesto noted that he had returned to work, and that he was available for the socially distanced, masks-on, outside patio interview we had discussed the previous month. Ernesto was extremely proud of his coffee shop and wanted me to try some of their specialty drinks and food. I agreed to meet him at his coffee shop.

After several weeks, since I had first messaged him to explain my dissertation and to ask if he would be willing to participate, Ernesto and I were finally sitting in front of each other. I answered his question about how my Dad was doing. I explained that he had undergone a tracheostomy, a procedure where surgeons make a hole through the patient's neck and into the windpipe to insert a tracheostomy tube that allows for air passage, after being on a ventilator for more than a month. The doctors told us that the tracheostomy would be less taxing on his body than the ventilator had been. My Dad's lungs were suffering from the destructive impacts of COVID-19, as he was experiencing full and partial lung collapses. After his tracheostomy procedure, my Dad had been transferred over to a specialized hospital where he remained in the ICU. I shared with Ernesto that my family and I were in a constant state of devastation as well as in awe of my dad's determination to improve. We nervously awaited his nurses' updates about his health every day. 
As I gave Ernesto this update, Jorge (pseudonym), one of Ernesto's business partners and head chef at the coffee shop, placed an iced horchata latte in front of me. I took a sip of my cold sweet drink, and Ernesto asked me how I liked it. It was very good, I told him, "one of the best I have ever had, actually." This was a significant comment coming from a someone who was studying Latinx-inspired coffee shops and who had tasted many horchata lattes throughout her research time. We then discussed which coffee shops had the best iced horchata lattes in town. The lighthearted talk brought smiles back on our faces for a second.

I then asked Ernesto about his Dad, remembering his message prior to our interview meeting. Leaning back into his chair and clasping his hands together in front of him, Ernesto shared that his Dad remained on a ventilator and was also suffering from collapsed lungs. He mentioned that he had a lot of hope despite the doctors' prediction that his Dad did not have long to live. In a passionate tone, Ernesto shared that he urged the doctors to not give up on his dad and to continue treating his dad every time he spoke to them.

At this moment, I had to take deep breaths to choke back tears. The shared connection between two Latinx millennial strangers, Ernesto and I, over COVID-19's impact on our fathers and family was overwhelming to me. Both of our fathers were immigrants. My father was from Mexico. Ernesto's father was from Guatemala. Both had hustled for decades in the United States to provide for their families. Now, both were on ventilators-one in San Diego and the other in Los Angeles. There was so much heaviness to process in the moment. In a strange way, there was comfort as well. I knew that I was not alone in navigating the despair and grief I was feeling. Others were experiencing life changes due to family members' battles with COVID-19. Ernesto's demeanor about our fathers made me feel hopeful that both of our fathers would show improvement soon.

After this conversation about our fathers' health statuses, I transitioned to my dissertation interview questions. I asked Ernesto about his business motivations, how his Latinx identity influenced the menu and decoration of the coffee shop, and how COVID had affected business strategies. After an hour of talking about his business and tasting the coffee shop's delicious ranchero avocado toast, a Mexican spin on the trendy avocado toast, I thanked Ernesto for his time and insight. I walked to my car and drove home on the 405 freeway with a mind full of thoughts. Not only was I thinking about the creative ways in which Ernesto's Latinx roots inspired his coffee shop, but I was thinking about the heartbreaking COVID-19 commonality that we shared. There was so much to digest after talking with Ernesto.

\section{Rethinking data collection approaches}

My interview with Ernesto inspired the following question: How do Latinx researchers navigate the process of data collection when our population of research interest, to which we belong, is being hard hit by unprecedented times? I realized that I needed to think deeply about this question because I was not seeing many academics or professional associations grapple with this. I had attended COVID19 research programming focused on how to conduct research virtually in order 
to make progress in graduate programs. However, none of the programming I was attending was acknowledging or addressing the trauma and grief I was experiencing. It truly seemed that although colleagues were aware that the pandemic was happening and disproportionally affecting communities of color, somehow, they did not consider that it was killing us or people we love. In addition, I found that the advice about doing research during the pandemic was centered on the researcher's ability to remain productive more than on thinking deeply about humane approaches to data collection with communities most affected by the pandemic.

Ernesto's story has stayed with me ever since the day I interviewed him. Our connection has been a reminder for me that, as scholars, we have the responsibility to continually think about our research participants in our data collection processes. Specifically, in order to take a more humane approach to qualitative data collection, we must practice thoughtful flexibility as a method in the research process. Otherwise, critical narratives are missed in theory building and policy applications. For instance, I wondered whether asking for Zoom interviews, as encouraged by academic events on how to continue doing research during COVID-19, was more convenient for the researcher or for the study participant. The access to time, a home, child care, a quiet space, a strong internet signal and the know-how of logging into Zoom is unequal. The assumption that access to these resources is equal is problematic, because it does not recognize how disparities have existed and have been magnified during the pandemic.

Rather than assume one method works for interviews, like only using Zoom, we need to prioritize our research participants and promote flexibility as a method. For me, it is crucial to think about my research participants-Latinx entrepreneurs navigating the stormy terrain of a COVID-19 economic recession. Many of my research participants are parents helping their children with their online schooling. I found that some of my participants, specifically mothers, preferred evening and weekend phone call interviews because of time and limited child care. For example, one single-mother interviewee cooked dinner for her two boys as she spoke to me one night. As she described the exhaustion she feels as a single mother and an entrepreneur, I heard the chopping of vegetables and the sizzling of raw ingredients hitting a hot pan. Another interviewee was feeding her baby and making sure her other two young kids were not getting into any trouble as she answered my interview questions. As she talked to me about how she and her husband started their coffee shop, she stopped intermittently to pick up items her baby had thrown to the floor. Although we were not on Zoom or in-person, I still picked up on sensorial aspects of our conversation that allowed me to imagine what the scenes at home may have looked like. The flexibility also allowed these entrepreneurs to participate, therefore ensuring that their narratives as working Latina mothers could be forever honored in my dissertation and future book.

How does the pandemic-relevant researcher flexibility I am discussing differ from flexibility that one may practice generally? Prior to the pandemic, I would have been flexible on which days to meet a participant. I would have tried to change my schedule around to ensure I could meet them in person. The pandemic pushed me to think beyond scheduling flexibility and consider my method of data collection itself. For example, perhaps a phone call is more accessible for a research participant than 
meeting in person or on Zoom. In conducting research during incredibly unusual times, scholars should consider this question and center research participants by asking their participants which form of research participation is most accessible to them. Although some may argue that this gives research participants too much decisionmaking in the data collection process, I believe that it is quite reasonable, especially considering the ways that academics benefit from incorporating participant interview quotes in journal articles that are later leveraged for their own career advancement. Scholars must consider how research participants' lives have shifted because of the unprecedented times and reflect on how their data collection methods can be reimagined.

\section{Centering self-care in our research journeys}

It is equally important to extend this thoughtful flexibility and care to ourselves as well. What gives me joy these days is seeing my father's strength as he recovers in his rehabilitation center in San Diego. At the age of sixty-five, he is relearning how to walk, eat, and talk. His progress has been nothing short of astonishing. As my family and I are making sense of how the pandemic changed our lives, I am focusing on my own healing. This means getting enough sleep, tending to my house plants, making healthy meals for myself, going on my daily walks, and continuing to see my health-care team. I am looking forward to the day when I am hooded as a doctora, and of having both my parents and my brothers there with me on graduation day. As I continue in my doctoral journey and beyond, I remember the many who lost their lives to COVID, including my abuelito and Ernesto's father. While we cannot control what the next few months and years have in store for us, we, Latinx researchers can seek ways to take care of ourselves and our loved ones, as well as practice humane and flexible data collection practices.

Acknowledgements I dedicate this article to Pablo Santellano and Jose Santellano. I thank my amazing research participants who have shared their stories with me. Thank you to Olivia Gonzalez, Cynthia Villarreal, and journal reviewers for providing helpful feedback. This work was supported by the Society for the Study of Social Problems (SSSP) Racial/Ethnic Minority Fellowship.

\section{References}

Centers for Disease Control and Prevention. 2021. Provisional COVID-19 deaths by race and Hispanic origin, and age. CDC, 17 June. https://data.cdc.gov/NCHS/Provisional-COVID-19-Deaths-by-Raceand-Hispanic-O/ks3g-spdg.

Lin, R. II, and L. Money. 2021. Latino COVID-19 Deaths Hit "HORRIFYING" Levels, Up 1,000\% since November in L.A. County. Los Angeles Times, 29 January. https://www.latimes.com/california/ story/2021-01-29/la-latino-covid-19-deaths-up-1000-percent-since-november.

Meeks, A., C. Maxouris, and H. Yan. 2021. "Human Disaster" unfolding in LA will get worse, experts say. CNN, 5 January. https://www.cnn.com/2021/01/05/us/los-angeles-county-california-humandisaster-covid/index.html.

Mester, M., and L. Lyster. 2020. ICU capacity drops to $0 \%$ in SoCal as state reports record number of daily COVID-19 infections, deaths. KTLA News, 17 December. https://ktla.com/news/california/ california-reports-record-number-of-daily-covid-19-infections-deaths/. 
Publisher's Note Springer Nature remains neutral with regard to jurisdictional claims in published maps and institutional affiliations.

Karina Santellano is a PhD candidate at the Department of Sociology at USC. In 2015, she earned her bachelor's degree in Sociology and a certificate in Latino/a studies from Duke University in Durham, North Carolina. She is a Bill and Melinda Gates Millennium Scholar, an American Association of Hispanics in Higher Education (AAHHE) Graduate Fellow, and a Society for the Study of Social Problems (SSSP) Racial/Ethnic Minority Graduate Fellowship recipient. Karina's upbringing as a daughter of Mexican immigrants and working-class background as well as her educational experiences as a first-generation college student have motivated Karina to become a sociologist of race/ethnicity, class, and culture. Her master's thesis examined the experiences of undocumented college students across the California public college and university system with their respective on-campus undocumented student resource centers. Karina's dissertation explores upwardly mobile and middle class Latinx capitalistic endeavors and cultural life in the United States. Her dissertation has received funding from the USC Graduate School Summer Fellowship, the USC Center for the Changing Family, the ASA Sociology of Culture Section, and the SSSP Racial/Ethnic Minority Fellowship Program. 